\title{
MICROELECTRODE RECORDS FROM A COCKROACH THORACIC GANGLION: SYNAPTIC POTENTIALS AND TEMPORAL PATTERNS OF SPIKE ACTIVITY*
}

\author{
EDWARD C. ROWE \\ Department of Zoology, University of Michigan, Ann Arbor, and Department of \\ Biology, Kansas State Teachers College, Emporia, Kansas, U.S.A.
}

(Received 6 Fanuary 1969)

\begin{abstract}
E.p.s.p.s and i.p.s.p.s $\dagger$ were recorded from cells in the cockroach third thoracic ganglion, using microcapillary electrodes filled with $3 \mathrm{M}$ $\mathrm{KCl}$.

2. Spike response patterns indicating complex integrative activities at the single cell level were also recorded.
\end{abstract}

\section{INTRODUCTION}

INSECT central nervous systems invite investigation because they use few neurons to integrate complex behavior, but electrophysiological records from insect central synapses have accumulated slowly. This is probably due to technical difficulties of recording from the small postsynaptic structures shown by anatomical studies to predominate in insect ganglia (Trujillo-Cenóz, 1959; Smith \& Treherne, 1963; Smith, 1965). The present study was initiated to add to the existing body of electrophysiological data on insect central synapses (Hagiwara \& Watanabe, 1956; Callec \& Boistel, 1965, 1966a, b, 1967; Iwasaki \& Wilson, 1966; Kendig, 1968). In collecting records of synaptic potentials, spike patterns giving evidence of ganglionic integration were also observed, and these are reported here.

\section{MATERIALS AND METHODS}

Adult cockroaches (Periplaneta fuliginosa) were beheaded and pinned ventral surface downward to a balsa block, and the dorsal cuticle and tissues overlying the ventral nerve cord were removed. Most of the peripheral nerves were cut to reduce muscle contractions. To permit penetration of microelectrodes into the third thoracic ganglion, a flap of connective tissue sheath was removed with watchmakers' forceps. The cord was perfused with aerated Hoyle's fluid (1953) modified by the addition of $100 \mathrm{~m}$-moles of sucrose/1. (Maynard, 1956).

Five stimulus inputs were available (Fig. 1). Electrical stimuli were delivered through silver-wire electrodes to the abdominal cord and to two thoracic connectives. Fine steel pin electrodes in the femur of each metathoracic leg served to stimulate peripheral branches of the main leg nerve [nerve 5 of Pringle (1939)].

* Based on a University of Michigan doctoral dissertation (Rowe, 1964). Some of this material appeared in an abstract (Rowe, 1965) or has been reviewed (Boistel, 1968).

$\dagger$ E.p.s.p.s = excitatory postsynaptic potentials; i.p.s.p.s $=$ inhibitory post-synaptic potentials. 
Hand-pulled microcapillary electrodes, filled with $3 \mathrm{M} \mathrm{KCl}$ and selected for small tip diameter under a water-immersion objective, were driven vertically into the ganglion by a micromanipulator. The microelectrode was coupled by a neutralized capacity preamplifier (Bak, 1958) to a D.C. oscilloscope.

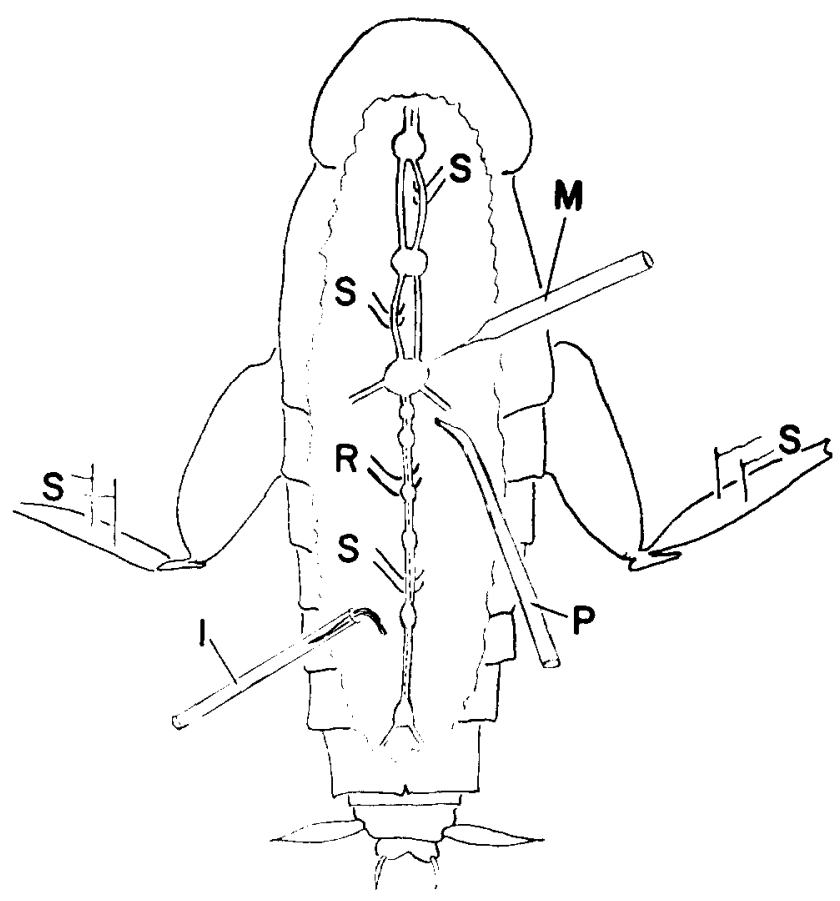

FIG. 1. Diagram of electrode placement in a cockroach prepared for recording. $\mathrm{S}=$ pair of stimulating electrodes. $\mathrm{R}=$ recording electrodes for monitoring general nerve cord activity. $\mathrm{M}=\mathrm{KCl}$-filled microeletrode in third thoracic

ganglion. $\mathbf{I}=$ indifferent electrode. $\mathbf{P}=$ tube delivering perfusion fluid.

The most successful electrodes for recording synaptic potentials had resistances of 30-100 $\mathrm{M} \Omega$ measured in perfusion fluid. Although these resistances suggest quite small recording tips, records of synaptic potentials were difficult to obtain, and most cells could be held in stable recording conditions no longer than $10 \mathrm{~min}$.

\section{RESUL'TS}

Records were obtained from 120 cells in the third thoracic ganglion. Abruptly revealed resting potentials characteristic of true intracellular records were infrequently observed. More commonly, approach to a unit was signaled by a gradual negative-going shift in baseline potential and by small, positive-going action potentials, which increased in amplitude as the electrode was pushed deeper into the ganglion. The d.c. baseline shifts were usually $30 \mathrm{mV}$ or less in amplitude, but resting potentials up to $70 \mathrm{mV}$ were occasionally recorded. Most of the spike 
potentials had amplitudes in the $2-30 \mathrm{mV}$ range. Small positive-going action potentials were also frequently recorded while an electrode was being withdrawn from the ganglion. Kendig (1968) obtained similar records from locust thoracic neurons and concluded the recording conditions were "quasi-intracellular", a term introduced by McIlwain \& Creutzfeldt (1967).

Though few of the records appear to be truly intracellular, it was sometimes possible to record pacemaker potentials and synaptic potentials, including the clearest i.p.s.p.s yet reported from an insect ganglion.

\section{Pacemaker potentials and multiple spike discharges}

Relatively few records of pacemaker activity in insect cells have been published. Favorable records of pacemaker potentials from six cockroach cells are shown in Figs. 2, 3A, 3B and 4A. In two of these cells each single spike was followed by an after-hyperpolarization, which evidently prevented further spikes (Figs. $2 \mathrm{~A}$ and $4 A)$. In a more common pattern, multiple spike discharges occurred during prolonged depolarizations (Figs. 2C, 3A and 3B). Apparently in these latter cases, each spike was followed by little or no hyperpolarization, so additional spikes were not blocked.

Multiple spike discharges were frequently observed in this study. Sometimes (as in Figs. 2C, 3A and 3B) bursts of spikes occurred during long depolarizations, but more frequently the spike discharge alone was observed (as in Fig. 3C). Intermittent repetitive bursts containing up to thirty spikes in each burst were recorded, but doublets and triplets of spikes were more common.

\section{Excitatory postsynaptic potentials}

The present results add to the available recordings of e.p.s.p.s from single postcerebral cells of insects (Hagiwara \& Watanabe, 1956; Callec \& Boistel, 1965, 1966a, b, 1967; Iwasaki \& Wilson, 1966; Kendig, 1968). Unusually clear e.p.s.p.s are shown in the responses of Fig. 4. The electrodes may have been intracellular since the amplitude of the action potentials was $44 \mathrm{mV}$. Each stimulus in Fig. 4B and $4 \mathrm{C}$ gave rise to a depolarization, and the larger depolarizations produced full spikes. In record $4 \mathrm{~B}$, three e.p.s.p.s were large enough to give rise to spikes but seven failed to do so. In record $4 \mathrm{C}$, all e.p.s.p.s but one gave rise, after varying latencies, to double spike responses.

In another unit (Fig. 5), small, irregular depolarizations gave rise to full spikes whenever the depolarizations reached a critical level. The animal was not given electrical stimuli. The irregular potentials are interpreted to be e.p.s.p.s produced by spontaneously active presynaptic neurons. A second group of small potentials in Fig. 5 is marked by arrows. 'These potentials have a shorter duration and more regular shape and fall into two amplitudes. They could be spikes from distant branches of the cell which fail to be propagated to all parts ("abortive spikes" of Bullock \& Terzuolo, 1957). However, since the electrode was probably not intracellular, these small potentials may be attenuated spikes from neighboring cells. 
Potentials, which may be unusually slowly developing e.p.s.p.s, were observed in the response of another cell (Fig. 6). Repetitive stimulation produced slow depolarizations which gave rise to habituating burst responses of three or four spikes. The latency to the first spike was highly variable and the timing of the later spikes was only loosely related to the timing of the later stimuli. In some respects the stimulus appeared to set off a pacemaker potential rather than an e.p.s.p., but some later stimuli accelerate the depolarization (see third stimuli in Fig. 6A and 6C). This particular response pattern was repeatable, provided the cell was allowed to rest several seconds between trials. "Triggered" bursts of spikes, such as those described by Fielden \& Hughes (1962) in insect abdominal interneurons, could be the result of slow depolarizations similar to these.

\section{Inhibitory responses}

Among the 120 cells studied, inhibitory responses were found in only three, including two units which behaved as if they received both excitatory and inhibitory input.

One cell (Fig. 7) provided not only the clearest example of spike inhibition in this study, but also displayed i.p.s.p.s and after-effects which persisted 6 sec after stimulation ceased. The unit was located near the ventral cell body region on the right side of the ganglion and was firing at regular intervals at about 50 spikes/sec before stimulation (top line of Fig. 7). Cumulative inhibition occurred (rest of Fig. 7) when the left leg nerve was stimulated at $5 / \mathrm{sec}$, and gradual recovery followed cessation of stimulation. The stimuli produced typical hyperpolarizing i.p.s.p.s, which drove the baseline potential below the critical level for producing spike potentials. For most of the first eight responses, i.p.s.p.s and spike inhibition lasted for about $50 \mathrm{msec}$ after each stimulus, but from stimulus 9 onward inhibition became progressively longer and less time-locked to the individual stimuli. From stimulus 14 onward the cell escaped inhibition only occasionally. Stimulation was stopped at stimulus 19 , but intermittent periods of spike inhibition continued during the $3 \mathrm{sec}$ of recovery shown in this record, and recovery was still incomplete $6 \mathrm{sec}$ after stimulation was stopped.

The pattern of this cumulative inhibitory response could be accounted for in the following way: The first few responses had component potentials of several amplitudes, and the period of synaptic bombardment was rather long (50 msec). This suggests that the responses were initially mediated by multiple pathways with varying synaptic delays. However, in the latter stages of the response, the individual i.p.s.p.s arrived at nearly regular intervals (at rates up to $175 / \mathrm{sec}$ ), and the potentials were nearly uniform in amplitude. This suggests the possibility that repeated stimulation led to recruitment of a single presynaptic inhibitory interneuron, which fired at a high, uniform rate.

For all units routine records were kept on microelectrode location with respect to surface features and penetration depth. Although these data were not usually helpful, they do give rise to some suggestions about the function of the unit just 

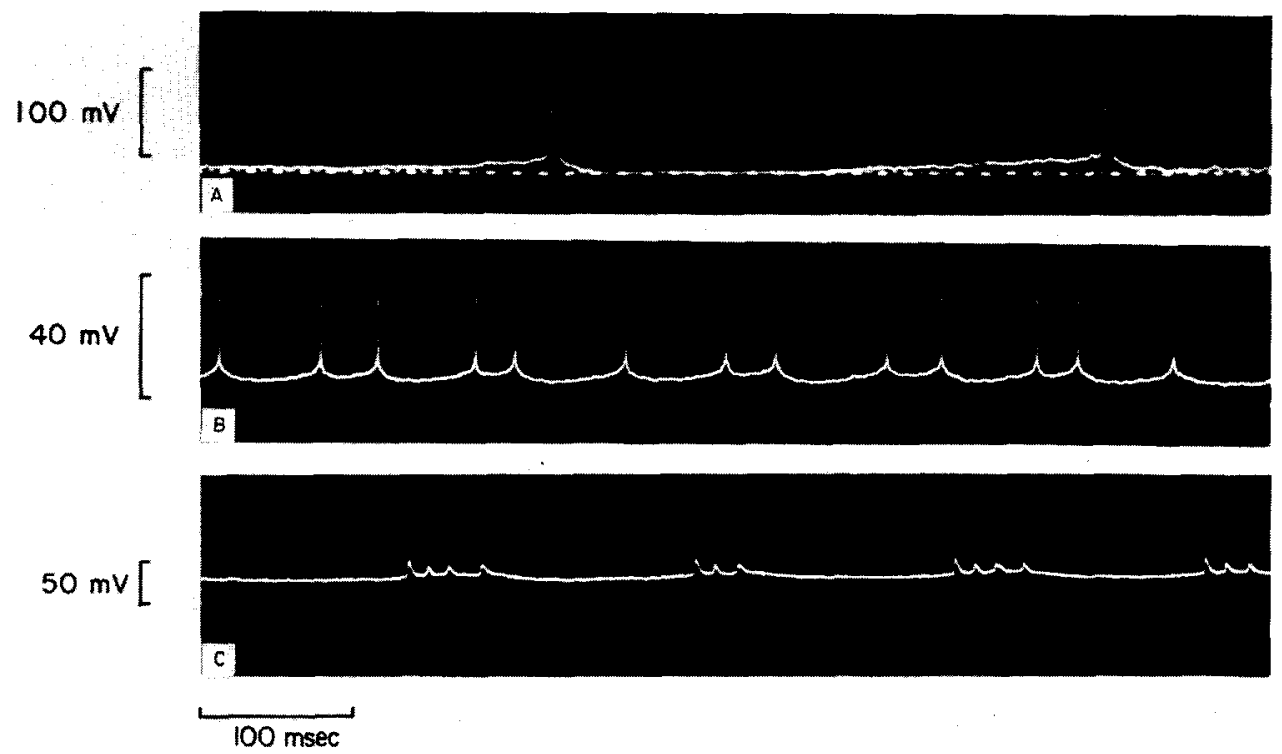

FIG. 2. Pacemaker potentials leading into spikes in three spontaneously active cells. In $\mathrm{A}$ and $\mathrm{B}$ each spike arises from a single depolarization. In $\mathrm{C}$ the multiple spike discharges arise from sustained depolarizations. Lower trace in record A: time calibration marks derived from $60 \mathrm{cycles} / \mathrm{sec}$ line voltage.

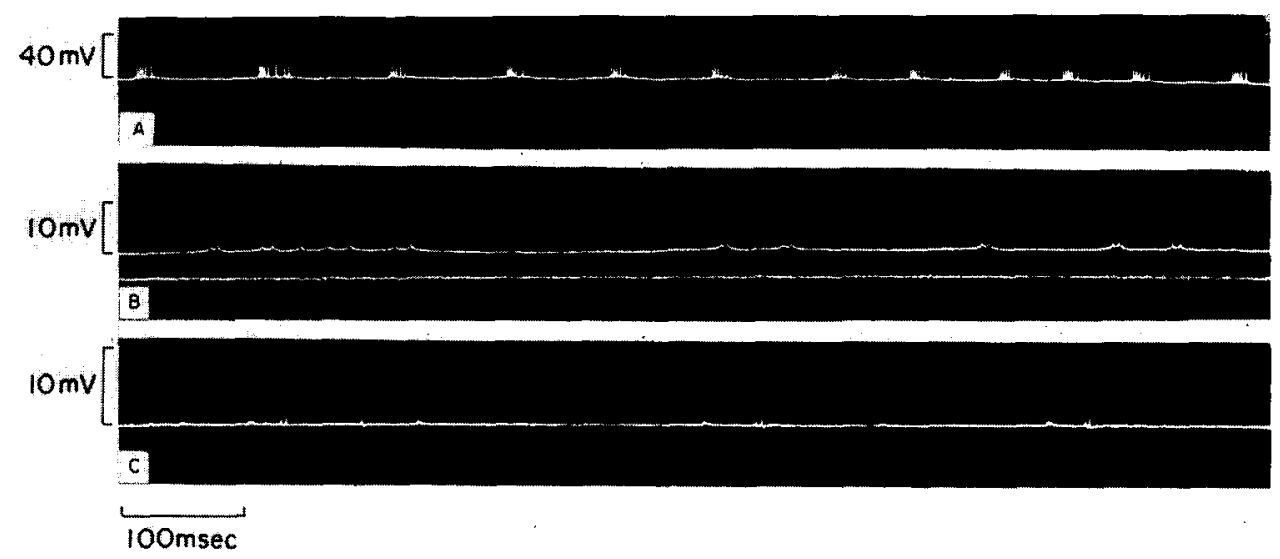

FIG. 3. Additional multiple spike discharges from spontaneously active cells. Sustained depolarizations are seen to give rise to doublets in $\mathrm{B}$ and to longer discharges in $\mathrm{A}$, but not to the doublets in $\mathrm{C}$. 


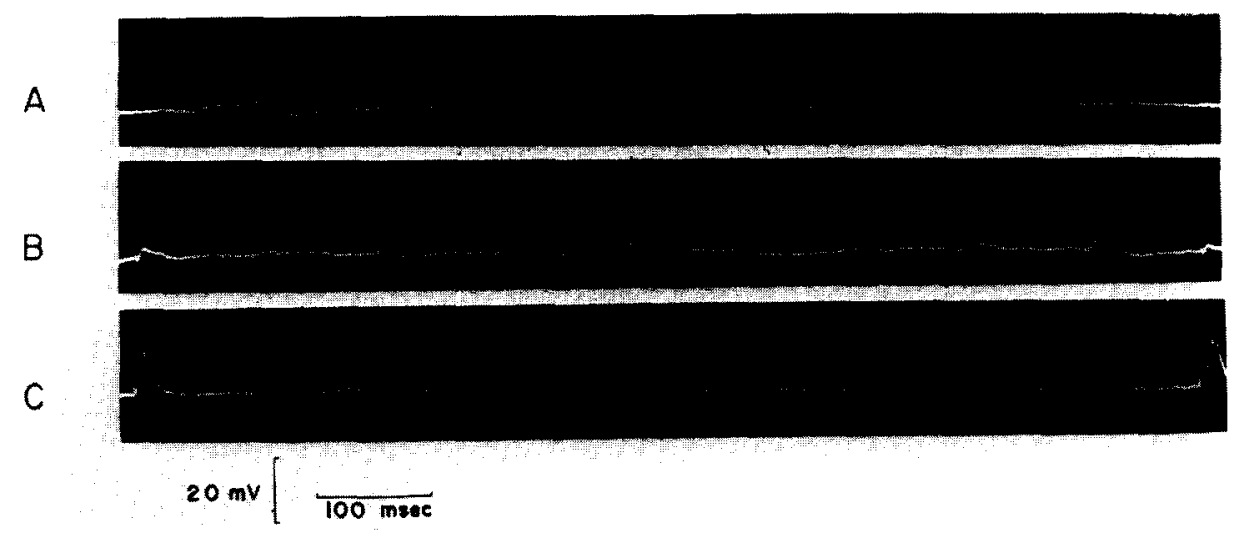

FIG. 4. Spontaneous pacemaker activity (A) and e.p.s.p.s and spikes in response to stimulation of the right thoracic connective (B) and left thoracic connective (C). Stimuli to spike latencies vary from 7 to 20 msec. Peaks of spikes went off screen.

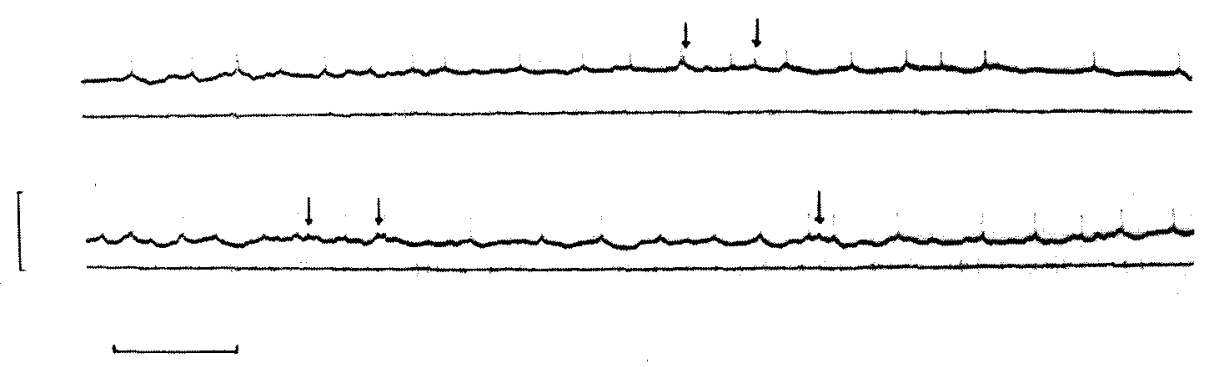

FIG. 5. Probable abortive spikes (marked by arrows) in record, which also shows spontaneous e.p.s.p.s giving rise occasionally to full spikes.

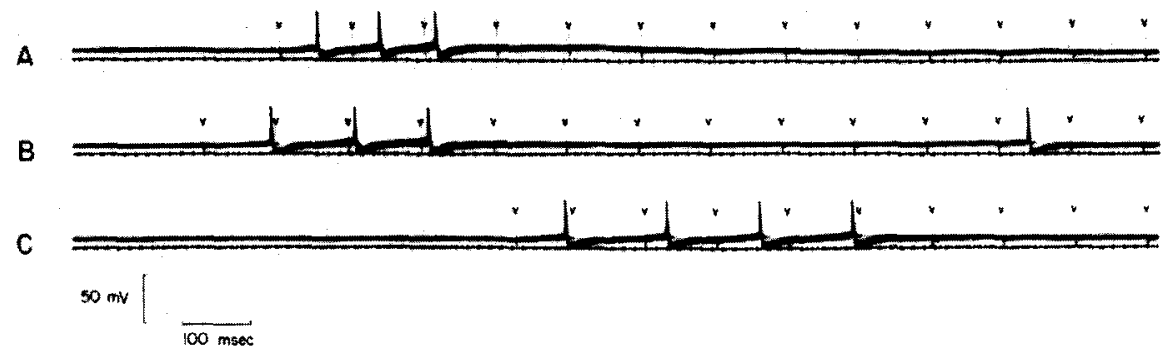

Fig. 6. Sustained depolarizations (e.p.s.p.s?) and habituating spike discharges in response to stimulation of right and left thoracic connectives ( $\mathrm{A}$ and $\mathrm{B}$ ) and $\mathrm{ab}-$ dominal cord (C). Stimulus artefacts marked by V's. First stimulus in each train produces a slowly developing depolarization. Some later stimuli (especially the third stimuli in A and C) appear to accelerate the depolarization. 


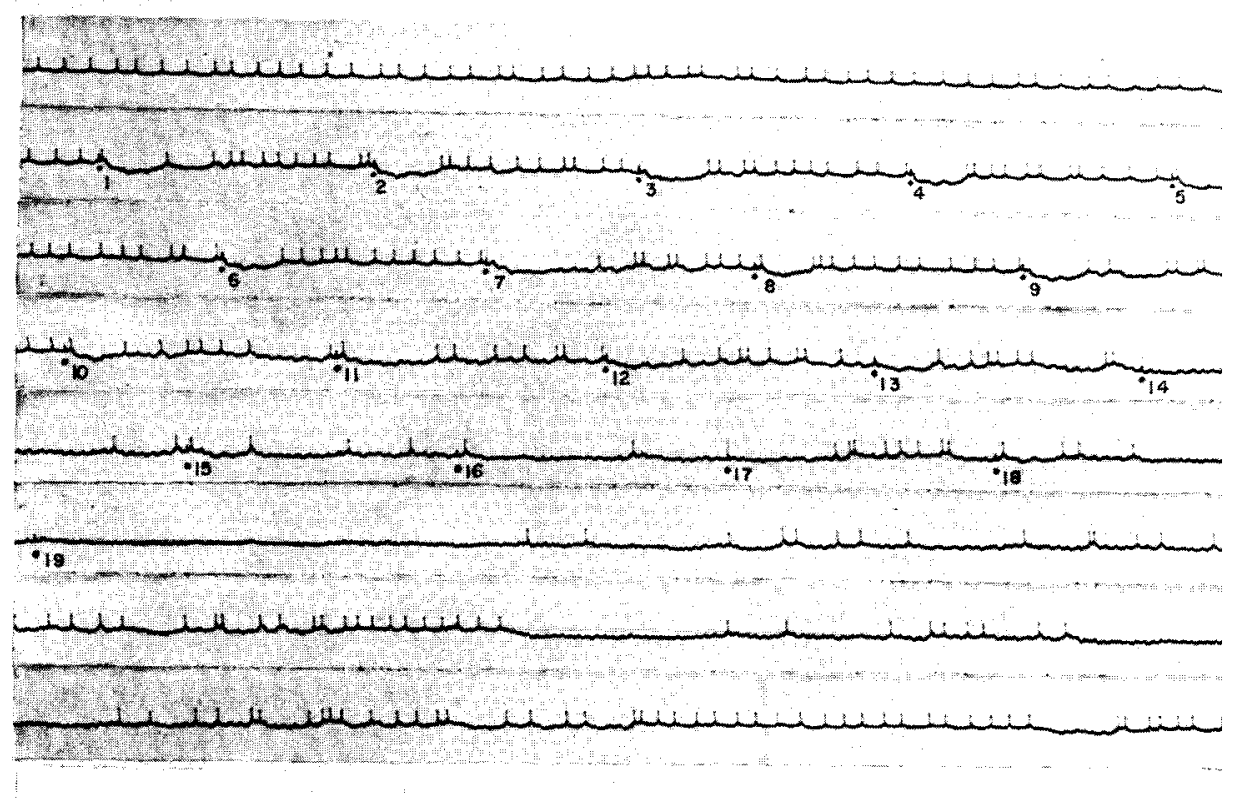

\section{$200 \mathrm{msec}$}

FIG. 7. I.p.s.p.s and cumulative inhibition in response to stimulation of left leg nerve 5. Microelectrode was near group of cell bodies with axons in right nerve 5. Top line of record shows spontaneous activity before stimulation. Originally faint stimulus artefacts have been retouched and marked by numbered dots. Inhibition is short-lived following first eight stimuli, but becomes nearly continuous by stimulus 19 , when stimulation was stopped. Spike amplitude, $6 \cdot 5 \mathrm{mV}$. Uninterrupted record. 


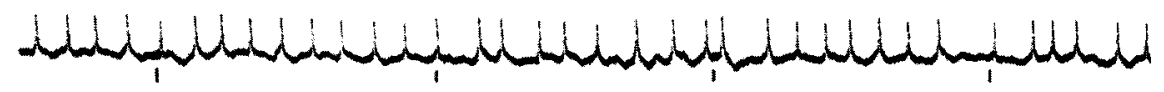

A
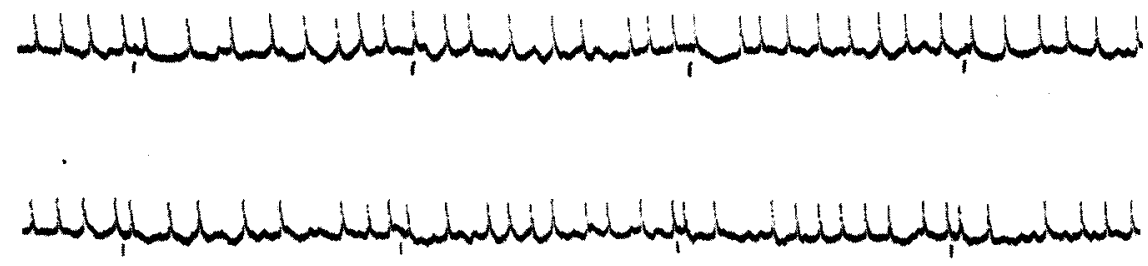

B
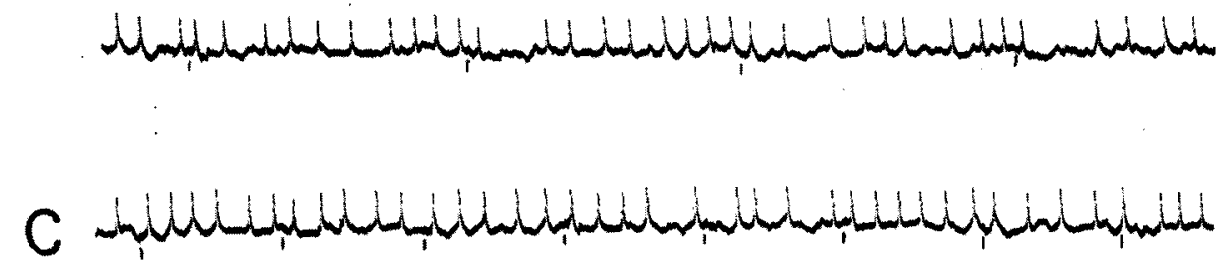

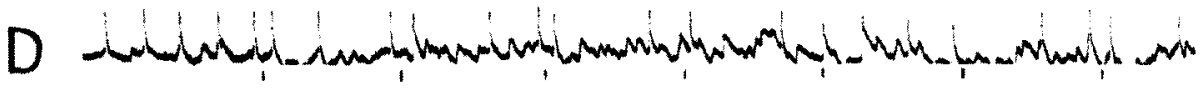
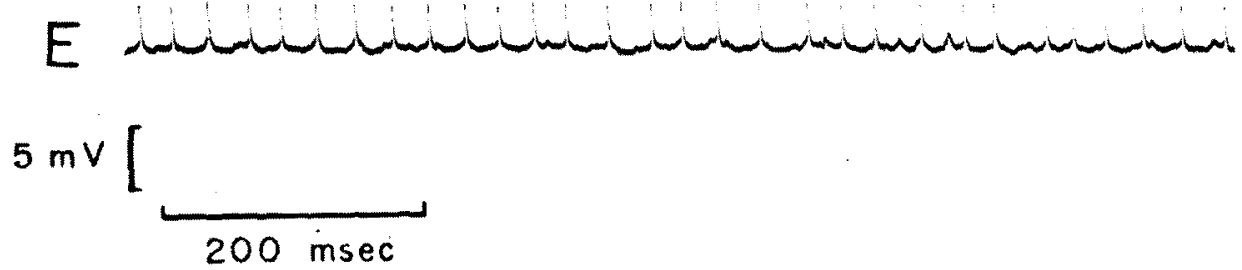

FIG. 8. Spontaneous spike discharge (E) and mixed excitation and inhibition in response to stimulation of left thoracic connective at four voltage-frequency combinations: (A) $5 \mathrm{~V}, 5 / \mathrm{sec}$; (B) $8 \mathrm{~V}, 5 / \mathrm{sec}$; (C) $5 \mathrm{~V}, 10 / \mathrm{sec}$; (D) $8 \mathrm{~V}, 10 / \mathrm{sec}$. Typical response in $A$ and $B$ consists of a spike following soon after the stimulus, then a period of spike inhibition, sometimes accompanied by prolonged hyerpolarizing potentials. Spike inhibition is strongest in record $D$, but unit still shows brief excitation immediately following stimuli. All five records show small potentials, some of which may be synaptic potentials. A.C. amplification (time constant of $180 \mathrm{msec}$ ) used for these records. 


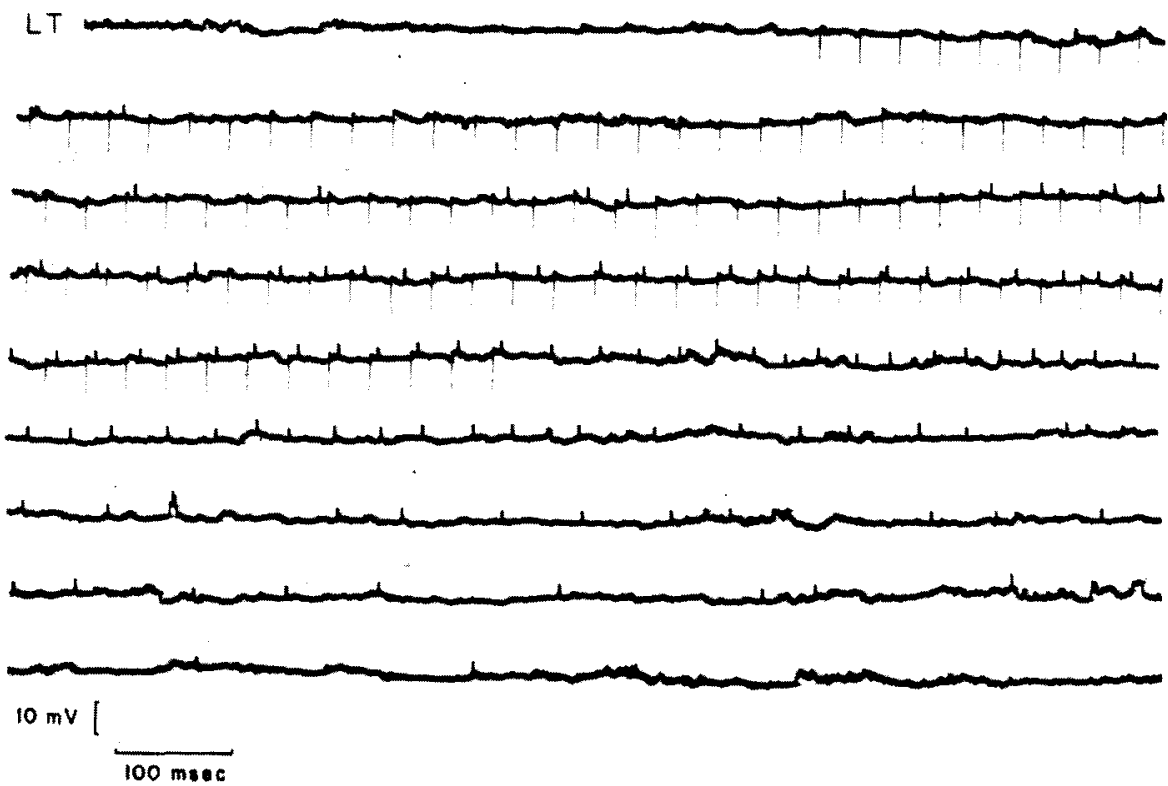

FIG. 9. Slowly facilitating response with gradually declining after-discharge which lasts for several seconds after stimulation stops. See Fig. 10 for graphical analysis. 

described. The data place the unit in a group of ventral cell bodies or in the neuropile just above. With the publication of Cohen \& Jacklet's (1967) map of motoneuron cell bodies in the third thoracic ganglion, it is possible to specify that the electrode tip was near the middle of the field of cell bodies for motoneurons of right leg nerve 5 . Since inhibition resulted from stimulation of nerve 5 in the opposite leg, it seems reasonable to speculate that it was caused by a pathway which has the function of ensuring that opposite homologous leg muscles usually alternate contractions during locomotion (Hughes, 1952).

The responses of another cell (Fig. 8) are less clear-cut than in the previous example, apparently because stimulation caused both excitation and inhibition in different mixtures, depending on the stimulus frequency and strength. A sample of spontaneous activity of the unit is shown in Fig. 8E. The typical response at each of four sets of stimulus parameters (Fig. 8A-D) was an early, loosely following spike, followed by a period of depressed spike production. Correlated periods of spike inhibition and hyperpolarization are best seen following the third, fifth and seventh stimuli in record $A$ and the second, sixth and eighth stimuli in record $B$. In response to the most active stimulation tried (Fig. $8 \mathrm{D}$ ), spike activity was greatly inhibited, although it is difficult to tell if the predominant small potentials are e.p.s.p.s or i.p.s.p.s. The lack of detailed correlation between membrane potential and spike production in Fig. 8A-D may be a consequence of the highly branched postsynaptic surface of arthropod neurons (see Discussion).

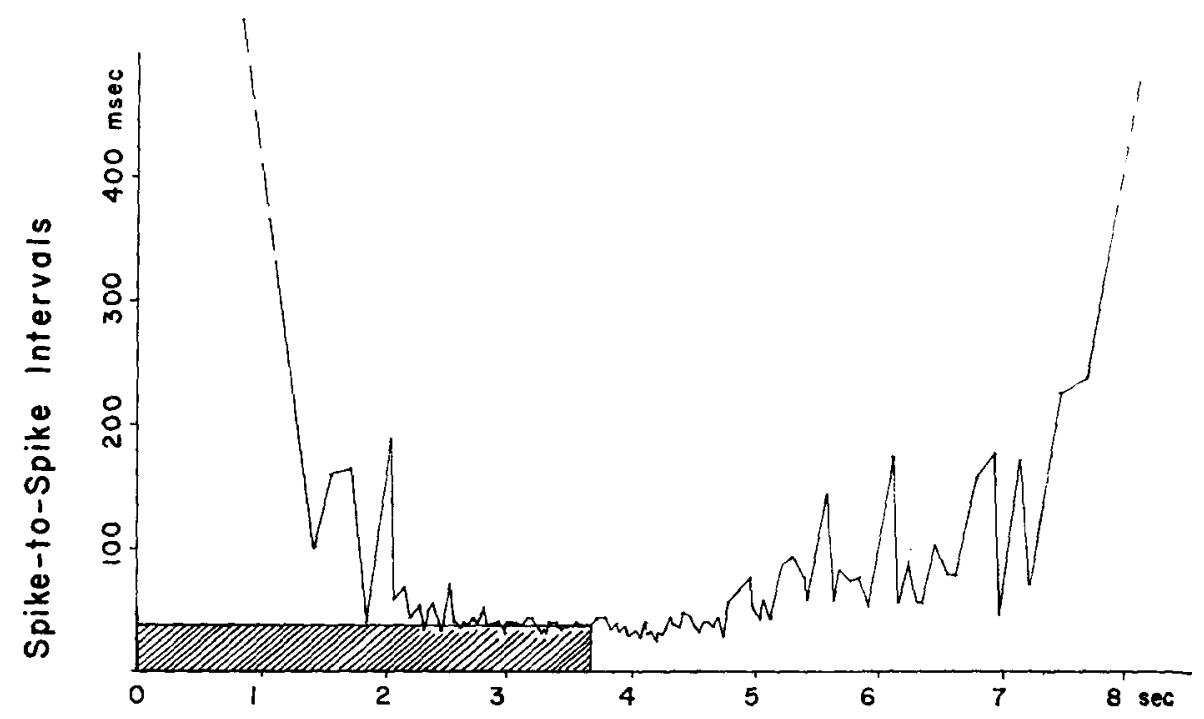

Time from Beginning of Stimulation

FIG. 10. Analysis of the response shown in Fig. 9. Interspike periods are plotted against time after stimulation started. The horizontal dimension of the shaded area represents time during which repetitive stimuli were being given and the vertical dimension represents the interval between stimuli. 


\section{Persistent responses}

Excitability changes lasting several seconds or longer in central neurons are of interest because they suggest the activation of whole behavioral systems. In the present study, two cells were notable for persistent responses. One, which showed cumulative inhibition during $4 \mathrm{sec}$ of stimulation, then gradual recovery over the first $6 \mathrm{sec}$ after stimulation ceased, was described with the inhibitory responses. The second example (Fig. 9) underwent gradual facilitation only after repeated stimulation, then continued firing after stimulation stopped. According to Luco's (1964) terminology, both exhibited "delayed" responses.

The record of Fig. 9 lacks synaptic potentials, contains much electrode noise and has small action potentials. The record is thus almost certainly extracellular. The unit was silent in the period before stimulation. Downward going artefacts mark the stimuli, which were applied to a thoracic connective at the rate of $30 / \mathrm{sec}$. The unit remained silent for the first $1.5 \mathrm{sec}$ of stimulation, then began to fire. The spike frequency gradually increased until, at $2.5 \mathrm{sec}$ of stimulation, the unit followed the stimuli $1: 1$. When stimulation was stopped at $3.7 \mathrm{sec}$ of stimulation, the unit continued to fire for another second at nearly the stimulus-induced rate, then its firing rate gradually declined over the next few seconds. Figure 10 shows how closely the spike intervals came to approximate the stimulus intervals during later stimulation and the first second of the after-discharge.

\section{DISCUSSION}

The present study gives evidence for processes within single insect neurons, including pacemaker activity, excitatory and inhibitory synaptic mechanisms, and complex spike response patterns. Some of the results are hard to interpret, because of the "quasi-intracellular" recording conditions or because information is lacking on the functions of inputs and outputs. However, the present results seem significant because they contribute to our understanding of what types of cellular integration processes might underlie some insect behavior.

Since information on cell processes in insect neuropiles has proved hard to obtain, it seems justified to discuss possible broader implications of activities observed in only a few units. This is done below in terms of the following issues in comparative neurophysiology: (1) electrical activities which might be due to insects' highly branched neurons; (2) synaptic excitation and inhibition mechanisms in insect central neurons; (3) possible information-carrying function of multiple spike discharges and (4) the general occurrence, and probable importance, of persistent responses.

Some phenomena recorded in the present study suggest that insects utilize neural integrative processes which are well known to occur in other invertebrates. Especially frequent comparisons are made to crustacean central neurons, since much is known about their physiology and in their morphology they closely resemble insect neurons. 


\section{Consequences of arthropod neuron morphology}

Insect and crustacean central neurons, unlike mammalian motoneurons, are highly branched and have numerous fiber-to-fiber synapses on spatially separate branches (Bullock \& Horridge, 1965). In crustacean cells these anatomical features give rise to two activity patterns, spike collisions and abortive spikes, which are considered to be of integrative significance because they permit single cells to behave as several sub-units. Spike collisions occur in crustacean cells in the allor-none conducting regions between widely separate synapses, permitting interactions not possible on the single postsynaptic surface of the mammalian motoneuron (Kennedy \& Mellon, 1964a, b). Abortive spikes, which invade some but not all of the branches of a cell, occur in crustacean cells (Bullock \& Terzuolo, 1957) and possibly add another intracellular integrative step. Spike collisions have not yet been found in insect cells. One record of the present study (Fig. 5) suggests abortive spikes do occur in insects.

In addition to being highly branched, the postsynaptic fibers of insect central neurons have small fiber diameters, usually less than $1 \mu$ and probably always less than $10 \mu$ (Hess, 1958; Trujillo-Cenóz, 1959; Smith \& Treherne, 1963; Smith, 1965). The small size of the postsynaptic fibers probably accounts for the paucity of synaptic records, the predominance of extracellular records and the short recording times found in this study and in some other recent microelectrode studies of insect neuropiles (Iwasaki \& Wilson, 1966; Kendig, 1968). A similar interpretation was reached by Hagiwara \& Watanabe (1956) who recorded full-size resting and action potentials from large motoneurons in the cicada ventral nerve mass but only potentials of smaller amplitude from small interneurons. Similarly, Callec \& Boistel (1966a) were able to improve records from cells of the sixth abdominal ganglion by decreasing tip electrode diameters, but apparently still had difficulties when recording from smaller nerve branches.

\section{Excitation and inhibition in insect neurons}

Single-cell recordings from insect neuropile are still not numerous, but the results of this and other microelectrode studies (reviewed by Boistel, 1968) show that insect synapses utilize postsynaptic potentials, as do many vertebrate, molluscan and crustacean synapses. Conformity to a general metazoan synaptic mechanism is also suggested by electron micrographs which show typical synaptic vesicles at many (but not all) junctions in the insect neuropile (Hess, 1958; 'Trujillo-Cenóz, 1959; Smith, 1965; Smith \& Treherne, 1965).

Inhibitory activitory must involve relatively few cells or be hard to detect for some technical reason. Although e.p.s.p.s have been reported several times from insect central cells (Hagiwara \& Watanabe, 1956; Callec \& Boistel, 1965, 1966a, b, 1967; Iwasaki \& Wilson, 1966; Kendig, 1968), only this study and Callec \& Boistel (1966b) have reported spike inhibition accompanied by hyperpolarizing potentials, and the present study is apparently the first to report i.p.s.p.s as clear as those shown in Fig. 7. Inhibitory response patterns were recorded only from a small 
minority of cells in this study, in spite of the suggestion from locomotor reflex studies (Pringle, 1940; Hughes, 1952) that reciprocal inhibition mechanisms occur in the ganglion studied. In Callec \& Boistel's (1966b) study, also, spike inhibition was observed in only 5 per cent of the cells.

Inhibitory responses were also hard to find in the early crustacean microelectrode studies (Preston \& Kennedy, 1960). Kennedy \& Mellon (1964a) have suggested that pure inhibitory responses might be rare because the inputs artificially stimulated usually contain both excitatory and inhibitory fibers, and spike inhibition or i.p.s.p.s may be obscured in the mixed responses. Records by Callec \& Boistel (1966b) containing both excitation and inhibition seem to fit this explanation. In their records from cells of the cockroach sixth abdominal ganglion, stimulation produced first a clear e.p.s.p., which often gave rise to a spike, then a period of depressed spike activity, accompanied by a long hyperpolarization which they were unwilling to call an i.p.s.p. Mixed excitatory and inhibitory input probably also explains one record of the present study (Fig. 8), in which stimulation was followed by an initial spike, then by a period of depressed spike activity. Smaller potentials in the record suggest both e.p.s.p.s and i.p.s.p.s but are not always clearly related to the spike activity. The loose correlation between synaptic potentials and spikes could be explained as another consequence of the multi-branched morphology of arthropod neurons; although spike activity of the cell might be influenced both by nearby and distant synapses, only synaptic potentials from nearby synapses would appear in the record.

\section{Multiple spike discharges}

A striking aspect of this and some other insect nervous system studies is the frequent recording of short discharges of spikes, particularly pairs and triplets of spikes (see Case, 1957; Fielden \& Hughes, 1962; Miller, 1965). While these patterns cannot yet be related to function in insects, there is increasing evidence from crustacean studies that multiple-spike discharges, particularly pairs, have a coding function. Wiersma \& Adams (1950) found crustacean myoneural junctions for which paired stimuli were more effective than evenly spaced stimuli at the same average frequency. More recently the spike pair interval has been shown to indicate ganglion of origin (Kennedy \& Mellon, 1964b) and number of spikes in discharge to indicate temperature (Grampp, 1963).

\section{Complex and persistent response patterns}

Two cells in the present study responded in a gradually facilitating pattern over several seconds of stimulation, then recovered just as gradually (Figs. 7 and 9). After-effects of similar duration were recorded by intracellular electrode from crayfish and Aplysia (Hughes \& Tauc, 1962; Kennedy \& Preston, 1963). Such persistent response patterns are to be expected when triggering a whole behavioral sequence such as a locomotor or flight reflex, and Luco (1964) has reported similarly complex responses from cockroach thoracic motoneurons. Persistent response patterns have also been recorded from single insect interneurons receiving input 
from abdominal mechanoreceptors (Fielden \& Hughes, 1962; Hughes, 1965). These latter studies have the advantage that function of the input is better known than in the present study but they were not carried out with electrodes capable of recording synaptic potentials. Thus, synaptic potentials underlying a complex response were not recorded (as they were in the cumulative inhibitory response of Fig. 7) but had to be inferred.

The generalization has often been made that invertebrate ganglia provide models for the study of neural integration, since they coordinate complex activities with few neurons. Tauc (1967) has argued that in selecting ganglia for basic studies, complexity of integrative capabilities is as important as low cell counts. Cockroach thoracic ganglia, each of which contains about 3000 neurons (Cohen \& Jacklet, 1967), are known to integrate leg movements in locomotion (Pringle, 1940) and to be capable of learning (Horridge, 1962; Eisenstein \& Cohen, 1965). The third thoracic ganglion studied here also appears to be a key ganglion in the control of ventilation and heart rate (Case, 1961; Smalley, 1963; Rounds, 1968). Thus, further examples of single cells showing complex and persistent responses, like those found in the present study and in Luco's (1964) study of motoneurons, are to be expected as more single unit studies are carried out on this ganglion.

Acknowledgements-I thank Dr. Donald Maynard for advice during the experiments reported here and Dr. Katherine Smalley for criticising this manuscript.

\section{REFERENCES}

BAK A. F. (1958) A unity gain cathode follower. Electroenceph. clin. Neurophysiol. 10, 745748.

Boistel J. (1968) The synaptic transmission and related phenomena in insects. Adv. Ins. Physiol. 5, 1-64.

Bullock T. H. \& Horridge G. A. (1965) Structure and Function in the Nervous Systems of Invertebrates, Vol. 2, pp. 854-882. Freeman, San Francisco.

Bullock T. H. \& Terzuolo C. A. (1957) Diverse forms of activity in the somata of spontaneous and integrating ganglion cells. $\mathcal{F}$. Physiol., Lond. 138, 341-364.

Callec J. J. \& Boistel J. (1965) Analysis with microelectrodes of the synaptic transmission at the level of the sixth abdominal ganglion of the cockroach, Periplaneta americana. In The Physiology of the Insect Nervous System (Edited by Treherne J. E. \& Beament J. W. L.), pp. 59-65. Academic Press, New York.

Callec J. J. \& Boistel J. (1966a) Etude de divers types d'activités électriques enregistrées par microélectrodes capillaires au niveau du dernier ganglion abdominal de la blatte, Periplaneta americana L. C. r. Séanc. Soc. Biol., Paris 160, 1943-1946.

Callec J. J. \& Borstel J. (1966b) Phénomènes d'excitation et d'inhibition synaptiques au niveau du 6ème ganglion abdominal de Periplaneta americana. C. r. Séanc. Soc. Biol., Paris 160, 2418-2424.

Callec J. J. \& Boistel J. (1967) Les effets de l'acétylcholine aux niveaux somatique et synaptique dans le cas du 6ème ganglion abdominal de Periplaneta americana. C. $r$. Séanc. Soc. Biol., Paris 161, 442-446.

CASE J. F. (1957) The median nerves and cockroach spiracular function. F. Insect Physiol. 1, $85-94$.

CASE J. F. (1961) Organization of the cockroach respiratory center. Biol. Bull., Woods Holt 121, 385. 
COHEN M. J. \& JACKLET J. W. (1967) The functional organization of motor neurons in an insect ganglion. Phil. Trans. R. Soc. B 252, 561-572.

EISENSTEIN E M. \& COHEN M. J. (1965) Learning in an isolated prothoracic insect ganglion. Anim. Behav. 13, 104-108.

Fielden A. \& Hughes G. M. (1962) Unit activity in the abdominal nerve cord of a dragonfly nymph. F. exp. Biol. 39, 31-44.

GRAMPP W. (1963) Multiple spike discharges of the slowly adapting neurons of the isolated crustacean stretch receptor organ. Acta physiol. scand. 59, Suppl. 213, 54-55.

Hagiwara S. \& Watanabe A. (1956) Discharges in motoneurons of cicada. $\mathcal{F}$. cell. comp. Physiol. 47, 415-428.

Hess A. (1958) The fine structure of nerve cells and fibers, neuroglia, and sheaths of the ganglion chain in the cockroach (Periplaneta americana). $\mathcal{F}$. biophys. biochem. Cytol. 4 , 731-742.

Horridge G. A. (1962) Learning leg position by the ventral nerve cord in headless insects. Proc. R. Soc. B. 157, 33-52.

Hoyle G. (1953) Potassium ions and insect nerve muscle. 7. exp. Biol. 30, 121-135.

Hughes G. M. (1952) The co-ordination of insect movements-I. The walking movements of insects. F. exp. Biol. 29, 267-284.

Hughes G. M. (1965) Neuronal pathways in the insect central nervous system. In The Physiology of the Insect Central Nervous System (Edited by Treherne J. E. \& Beament J. W. L.), pp. 79-112. Academic Press, New York.

Hughes G. M. \& TAUC L. (1962) Aspects of the organization of central nervous pathways in Aplysia depilans. F. exp. Biol. 39, 45-69.

IWASAKI S. \& WiLSON D. M. (1966) Neuropile potentials following wing sensory nerve stimulation in locusts. Comp. Biochem. Physiol. 17, 693-695.

Kendig J. J. (1968) Motor neurone coupling in locust flight. F. exp. Biol. 48, 389-404.

Kennedy D. \& Melion DeF. (1964a) Synaptic activation and receptive fields in crayfish interneurons. Comp. Biochem. Physiol. 13, 275-300.

Kennedy D. \& Mellon DeF. (1964b) Receptive-field organization and response patterns in neurons with spatially-distributed input. In Neural Theory and Modeling (Edited by Reiss R. F.), pp. 400-413. Stanford University Press, Stanford, California.

Kennedy D. \& Preston J. B. (1963) Postactivation changes in excitability and spontaneous firing of crustacean interneurons. Comp. Biochem. Physiol. 8, 173-179.

Luco J. V. (1964) Plasticity of neural function in learning and retention. In Brain Function, Vol. II : RNA and Brain Function; Memory and Learning (Edited by BRAzIER M. A. B.), pp. 135-159. University of California Press, Los Angeles.

McIllain J. T. \& CREUTzFeldt O. D. (1967) Microelectrode study of synaptic excitation and inhibition in the lateral geniculate nucleus of the cat. $\mathcal{F}$. Neurophysiol. 30, 1-21.

MaYnard D. M. (1956) Electrical activity in the cockroach cerebrum. Nature, Lond. 177, 529-530.

Miller P. L. (1965) The central control of respiratory movements. In The Physiology of Insect Central Nervous Systems (Edited by Treherne J. E. \& Beament J. W. L.), pp. 141-155. Academic Press, New York.

Preston J. B. \& Kennedy D. (1960) Integrative synaptic mechanism in the caudal ganglion of the crayfish. F. gen. Physiol. 43, 671-681.

Pringle J. W. S. (1939) The motor mechanism of the insect leg. F. exp. Biol. 16, 220-231.

Pringle J. W. S. (1940) The reflex mechanism of the insect leg. $\mathcal{F}$. exp. Biol. 17, 8-17.

Rounds H. D. (1968) KCl-induced "spreading depression" and ventilation in the cockroach. Comp. Biochem. Physiol. 24, 653-655.

Rowe E. C. (1964) Microelectrode records from an insect thoracic ganglion. Ph.D. dissertation, University of Michigan.

Rowe E. C. (1965) Excitatory and inhibitory postsynaptic potentials recorded from cells in an insect central nervous system. Am.Zool. 5, 202. 
Smalley K. N. (1963) The neural regulation of respiration in the cockroach Blaberus craniifer. Ph.D. dissertation, University of lowa.

SMITH D. S. (1965) Synapses in the insect nervous system. In The Physiology of the Insect Central Nervous System (Edited by Treherne J. E. \& Beament J. W. L.), pp. 39-57. Academic Press, New York.

Smith D. S. \& Treherne J. E. (1963) Functional aspects of the organization of the insect nervous system. Adv. Insect Physiol. 1, 401-484.

Smrth D. S. \& Treherne J. E. (1965) The electron microscopic localization of cholinesterase activity in the central nervous system of an insect, Periplaneta americana L. $\mathcal{~}$. Cell Biol. 26, 445-465.

Tauc L. (1967) Transmission in invertebrate and vertebrate ganglia. Physiol. Rev. 47, 521-593.

Trujillo-Cenóz O. (1959) Study on the fine structure of the central nervous system of Pholus labruscoe L. (Lepidoptera). Z. Zellforsch. mikrosk. Anat. 49, 432-446.

Wiersma C. A. G. \& Adams R. T. (1950) The influence of impulse sequence on the contraction of different crustacean muscles. Physiol. comp. Oecol. 2, 20-33.

Key Word Index-Cockroach nerves; insect nerves; Periplaneta americana; electrical activity of nerves; insect e.p.s.p.; insect i.p.s.p.; synaptic potentials. 